\title{
Are the instruments for quality of life assessment comparable between cultures? No
}

\author{
Swagata Tripathy ${ }^{1 *}$ and Sheila Nainan Myatra ${ }^{2}$
}

(c) 2020 Springer-Verlag GmbH Germany, part of Springer Nature

The concept of quality of life (QOL) goes beyond health. The WHO definition of QOL includes six domains of which four are related to health status and two are personal (environment, personal values/beliefs) [1]. Being objective, the first four are considered easier to assess and quantify. They are often the focus of health-related quality of life (HRQOL) questionnaires. The last two domains are affected by culture and change with age, time and situations, thus raising the question whether QOL assessments are comparable between cultures (Fig. 1) [2].

Most instruments of QOL are developed in the USA or the UK in English and need cross-cultural adaptation (CCA) to various European, Asian or other languages and cultures [3]. CCA of instruments needs to consider myriad attributes of quality of life important to people: income and family relations, appreciation for and utility of life, religious beliefs regarding karma, life after death, etc. The main questions that arise regarding cross-cultural QOL adaption are: Is the concept of QOL identical or equivalent across the cultures in question?; is it measurable across different cultures with the same QOL instrument?; and is the application of these instruments similar across cultures?

The concept of equivalence of various domains of QOL across cultures is debated, with Herdman et al. finding 19 different interpretations [4]. The 'particularists' consider the implication and interpretation of a disease state intensely culture bound, precluding QOL application outside cultural boundaries. The 'absolutists' oppose this-health is the same across humanity, and culture has no effect on HRQOL perception. In between, are the

*Correspondence: tripathyswagata@gmail.com

${ }^{1}$ Department of Anesthesia and Intensive Care, All India Institute of Medical Sciences, Bhubaneswar, Odisha, India

Full author information is available at the end of the article universalists who consider QOL domains to be uniform across humanity-careful linguistic translation may allow cross-cultural use of an instrument [5].

In spite of identifying thirty-one guidelines for CCA of questionnaires, Epstein et al. found no consensus in the methods of CCA. The use of focus groups and committees for CCA is common, but there is less evidence for back translation [6]. Studies have shown cross-cultural variations in response to such questionnaires. Cheung et al. [7] found that low 'jingshen' (Chinese for energy, but having connotations for spiritual vigour) used in a cancer therapy questionnaire was reported less frequently than low 'energy' used in the English version. Theuns et al. [8] found that only 11 of 24 constructs of the WHOQOLBref, an abbreviated version of the original WHO QOL questionnaire, had measurement equivalence when compared among Iranian and Belgian students. Psychological and physical constructs like satisfaction with sleep, capacity for work, etc. were interpreted differently. Scott et al. found differences in how the European Organization for Research and Treatment for Cancer quality of life Questionnaire (EORTC) QLQ-C30 was answered internationally; results from East Asia and Eastern Europe were most different. Respondents from Asia were culturally more likely to agree with questions and less likely to choose extreme values in rating scales [9]. CCA guidelines often place an undue emphasis on sematic equivalence and psychometric validation at the cost of cultural equivalence [3].

Adaptation and validation are two different entities. For example, when one is adapting an instrument to a particular population in order to ensure cultural equivalence, altering the items may change the psychometric properties of the instrument. Principal bodies discourage this [4]. In instances where cultural equivalence has been tested, the resulting items have differed considerably from the parent items [10].

\section{6 Springer}




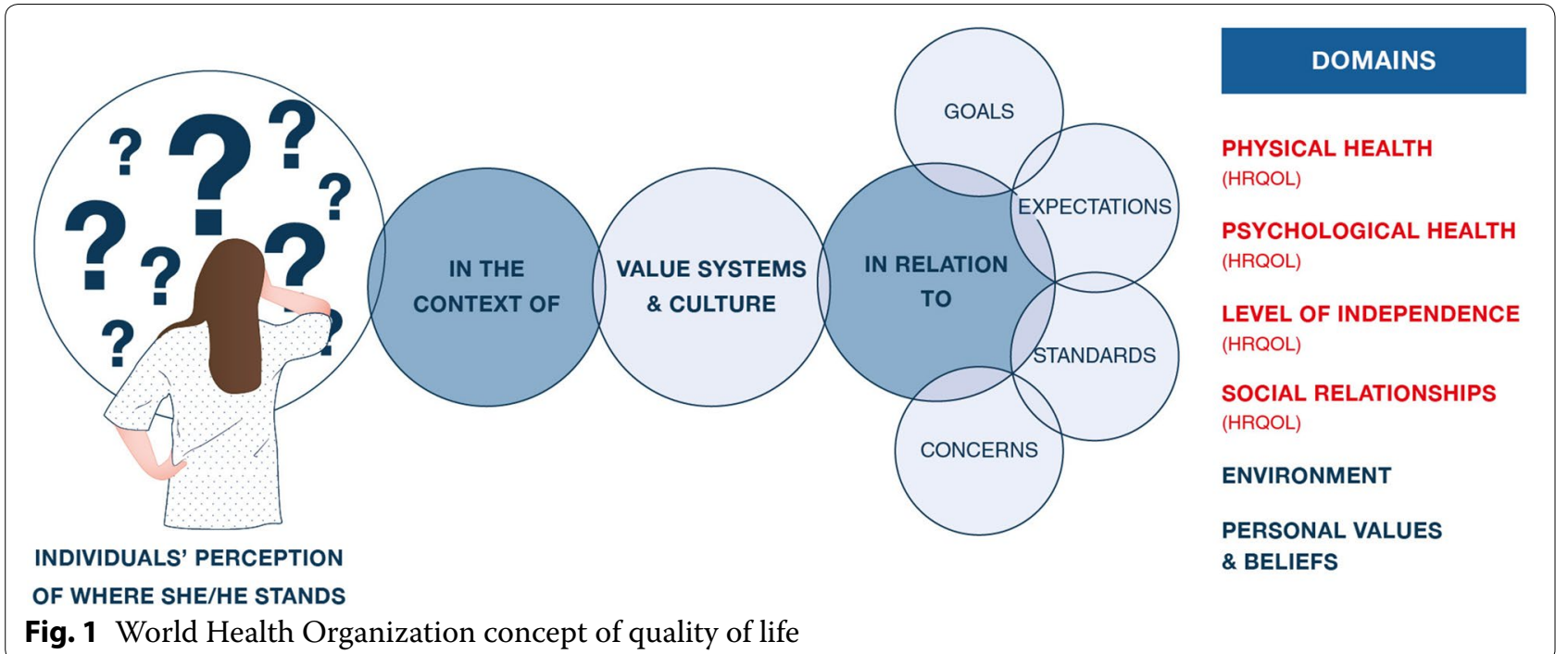

Our experience with CCA, administration and validation of the Euro Quality of Life 5 Dimensions-3 Levels (EQ5D-3L) based on the universalist approach brought deep insights into the real-life issues with CCA. We chose EQ5D-3L, as it offers flexibility in administration and has been used widely in critical care research. It was chosen over the $5 \mathrm{~L}$ version after a preliminary survey demonstrated that more choices therein were 'fatiguing' for our patients. Our request for collaboration to translate the instrument in Odia according to their guidelines was accepted. Following a detailed examination of our reports by the EuroQol group at all stages, including cognitive debriefing interviews aimed to prevent misinterpretations, psychometric properties, etc., the final Odia version was accepted [11]. The process was exhaustive and truly increased our appreciation for linguistic nuances and interpretative differences in our mother tongue.

Recently, this version has been administered to more than 500 patients discharged from our ICU by a clinical psychiatrist. She reported having to clarify to patients the 'anxiety' and the visual analogue scale parts. The (most appropriate) translated word for 'anxiety' had nuanced cultural connotations, and the instruction to think of VAS as a 'scale' did not find acceptance as culturally our people think of scales as fractions of currency, e.g. 'half rupee reduction' means a 50\% decrease. These were areas where we had faced issues during the CCA process, but did not have an option of replacing with culture-specific terms. When the posttraumatic stress disorder and anxiety/ depression domain results of our ICU patients emerged to be lower than those from western data (even though factors associated with higher psychiatric morbidity were similar) and eerily similar to a study from another developing country [12], we were left pondering. Is this difference true or a chink in the cultural adaptation? Interestingly patients who reported 'dreams' or 'flashes of memory' like 'feeling of a tube in my mouth every time I brush my teeth' were convinced that these events were not unpleasant and had a high level of acceptance and gratitude towards the medical team, who they felt helped them by doing these interventions despite residual effects [13].

Though the nature of trauma may be similar for ICU patients across cultures and ethnicities, patients' sociocultural fabric, acceptance of symptoms and coping mechanisms may vary. Reports from the tsunami in India in 2004 have shown that the majority of people use a cognitive framework, 'will of God', prayers, etc. as coping mechanisms to endure traumatic experiences [14]. Factors such as literacy and concordance between the written and spoken language may introduce error into the target language version of the instrument [15]. An individual may adapt to a worse health state due to resilience or other sociocultural constructs. This recalibration of expectations leads to a response shift in patient reported outcomes (PROs) and is known as the disability paradox. The process of rigorous CCA of an instrument is perhaps more challenging than meets the eye. Then again, perhaps certain culture-dependent attributes are just not amenable to comparison.

In conclusion, we feel that while one may compare many domains (universally similar for all humans) with instruments which have undergone careful translation and CCA according to guidelines, certain aspects of QOL are perhaps too culture-specific. They might better be identified and removed from a comparison between 
cultures. This approach, however, might bring with it newer issues: not surprising when studying something as variable and disparate as human nature!

\author{
Author details \\ ${ }^{1}$ Department of Anesthesia and Intensive Care, All India Institute of Medi- \\ cal Sciences, Bhubaneswar, Odisha, India. ${ }^{2}$ Department of Anesthesiology, \\ Critical Care and Pain, Tata Memorial Hospital, Homi Bhabha National Institute, \\ Mumbai, India.
}

\section{Funding}

Not applicable.

\section{Compliance with ethical standards}

\section{Conflicts of interest}

ST and SNM have no competing interests.

\section{Ethical approval}

Not applicable.

\section{Publisher's Note}

Springer Nature remains neutral with regard to jurisdictional claims in published maps and institutional affiliations.

Received: 9 January 2020 Accepted: 9 March 2020

Published online: 27 March 2020

\section{References}

1. EUPATI (2020) Measuring health-related quality of life (HRQoL). https:// www.eupati.eu/health-technology-assessment/measuring-health-relat ed-quality-life-hrqol/. Accessed 14 Feb 2020

2. Dijkers MP (2003) Individualization in quality of life measurement: instruments and approaches. Arch Phys Med Rehabil. https://doi.org/10.1053/ apmr.2003.50241

3. Prakash V, Shah S, Hariohm BA, Ashok K, Patel R (2019) Cross-cultural adaptation of patient-reported outcome measures: a solution or a problem? Ann Phys Rehabil Med 62:174-177. https://doi.org/10.1016/j.rehab .2019.01.006

4. Herdman M, Fox-Rushby J, Badia X (1997) "Equivalence" and the translation and adaptation of health-related quality of life questionnaires. Qual Life Res 6:237-247
5. Schmidt S, Bullinger M (2003) Current issues in cross-cultural quality of life instrument development. Arch Phys Med Rehabil. https://doi. org/10.1053/apmr.2003.50244

6. Epstein J, Santo RM, Guillemin F (2015) A review of guidelines for crosscultural adaptation of questionnaires could not bring out a consensus. $J$ Clin Epidemiol 68:435-441

7. Cheung YB, Thumboo J, Goh C, Khoo KS, Che W, Wee J (2004) The equivalence and difference between the English and Chinese versions of two major, cancer-specific, health-related quality-of-life questionnaires. Cancer 101:2874-2880. https://doi.org/10.1002/cncr.20681

8. Theuns P, Hofmans J, Mazaheri M, Van Acker F, Bernheim JL (2010) Crossnational comparability of the WHOQOL-BREF: a measurement invariance approach. Qual Life Res 19:219-224. https://doi.org/10.1007/s1113 6-009-9577-9

9. Scott N, Fayers P, Aaronson N, Bottomley A, Graeff AD, Groenvold M et al (2006) The use of differential item functioning analyses to identify cultural differences in responses to the EORTC QLQ-C30. Qual Life Res 16:115129. https://doi.org/10.1007/s11136-006-9120-1

10. Ganguli M, Ratcliff G, Chandra V, Sharma S, Gilby J, Pandav R et al (1995) A hindi version of the MMSE: the development of a cognitive screening instrument for a largely illiterate rural elderly population in India. Int J Geriatr Psychiatry 10:367-377. https://doi.org/10.1002/gps.930100505

11. Tripathy S, Hansda U, Seth N, Rath S, Rao PB, Mishra TS, Kar N (2015) Validation of the euroqol five-dimensions-three-level quality of life instrument in a classical Indian language (Odia) and its use to assess quality of life and health status of cancer patients in Eastern India. Indian J Palliat Care 21(3):282-288

12. Mafra JMES, Silva JMD, Silveira LTYD, Fu C, Tanaka C (2016) Quality of life of critically ill patients in a developing country: a prospective longitudinal study. J Phys Ther Sci 28:2915-2920. https://doi.org/10.1589/jpts.28.2915

13. Tripathy S, Kar N (2019) Psychiatric morbidity in the post-ICU patientethnocultural differences. Indian J Crit Care Med 23:440-441. https://doi. org/10.5005/jp-journals-10071-23244

14. Asnaani A, Hall-Clark B (2017) Recent developments in understanding ethnocultural and race differences in trauma exposure and PTSD. Curr Opin Psychol 14:96-101. https://doi.org/10.1016/j.copsyc.2016.12.005

15. Orley JH, Kuyken W (eds), World Health Organization, Division of Mental Health, Fondation IPSEN pour la recherche thérapeutique \& International Quality of Life Assessment in Health Care Settings Meeting (1993: Paris, France) (1994) Quality of life assessment: international perspectives: proceedings of the joint meeting organized by the World Health Organization and the Foundation IPSEN in Paris, July 2-3 1993. Springer, Berlin. https://apps.who.int/iris/handle/10665/41833 